Article

\title{
A Hybrid Optimization Approach for Power Loss Reduction and DG Penetration Level Increment in Electrical Distribution Network
}

\author{
Teketay Mulu Beza ${ }^{\mathbb{D}}$, Yen-Chih Huang ${ }^{\mathbb{D}}$ and Cheng-Chien Kuo *D \\ Department of Electrical Engineering, National Taiwan University of Science and Technology, \\ 43, Sec. 4, Keelung Rd., Taipei 10607, Taiwan; mteke24@gmail.com (T.M.B.); \\ m10707205@gapps.ntust.edu.tw (Y.-C.H.) \\ * Correspondence: cckuo@mail.ntust.edu.tw; Tel.: +886-920881490; Fax: +886-227376688
}

Received: 23 October 2020; Accepted: 13 November 2020; Published: 17 November 2020

check for updates

\begin{abstract}
The electrical distribution system has experienced a number of important changes due to the integration of distributed and renewable energy resources. Optimal integration of distributed generators (DGs) and distribution network reconfiguration (DNR) of the radial network have significant impacts on the power system. The main aim of this study is to optimize the power loss reduction and DG penetration level increment while keeping the voltage profile improvements with in the permissible limit. To do so, a hybrid of analytical approach and particle swarm optimization (PSO) are proposed. The proposed approach was tested on 33-bus and 69-bus distribution networks, and significant improvements in power loss reduction, DG penetration increment, and voltage profile were achieved. Compared with the base case scenario, power loss was reduced by $89.76 \%$ and the DG penetration level was increased by $81.59 \%$ in the 69 -bus test system. Similarly, a power loss reduction of $82.13 \%$ and DG penetration level increment of $80.55 \%$ was attained for the 33-bus test system. The simulation results obtained are compared with other methods published in the literature.
\end{abstract}

Keywords: distributed generation; distribution network reconfiguration; power loss reduction; optimization; voltage stability index

\section{Introduction}

Energy is a major requirement for the economic development of a country. It is available in various forms in nature, but the most significant type is electrical energy, which has become integral to daily life [1,2]. However, electrical power distribution companies face substantial difficulties due to increasing load demand and deficiency of capital investment in transmission and distribution networks. In addition, the current transmission and distribution networks in most countries are relatively old [3].

Power loss reduction and voltage profile improvement are vital components of power systems due to existing distribution system contingency, financial losses of utilities, and power system interruptions [4]. Because of the steady growth in energy demand and substantial increase in the use of distributed generation, utilities are exploring alternatives to improve the technical specifications of the distribution networks in terms of power losses, customer interruption costs, and voltage stability, while increasing the penetration level of distributed generators (DGs). Optimal allocation of DGs, capacitor placement, and distribution network reconfiguration (DNR) are effective means of enhancing the reliability of power systems [5,6].

Recently, DGs are becoming increasingly attractive to utilities and consumers because these units produce energy close to the load, and are more efficient (less losses), easier to site and have less environmental impact [7-10]. DGs are primarily installed on the distribution and sub-transmission level networks. Their main technical benefits include [11-15]: 
- Power loss reduction due to the proximity of load and generation.

- Voltage profile improvement.

- Improved reliability and security.

- Pollutant emission reduction from central power plants.

- Long term deferral of investment in transmission system expansion.

- Increasing loadability.

Previous research $[12,16,17]$ strongly recommends the effective use of the existing distribution infrastructure with minimum expenditure to enhance the capacity of existing systems. It has been observed that the loadability or capacity of the distribution system is commonly restricted by two factors, i.e., thermal and voltage limits. The current carrying capacity of the conductor is called the thermal limit. The current carrying capacity is highly dependent on the maximum conductive design temperature of the conductor, which is also determined by the insulation class used [16]. However, the voltage limit is the maximum permissible voltage deviation for proper operation of the power system and connected load. The study in $[17,18]$ indicated that the maximum load handling capacity of the distribution network is mainly dependent on the voltage limit rather than the thermal limit. Based on this previous research, the voltage limit constraints are prioritized in this paper.

It has also been noted that, because of its increasing use, renewable power generated from solar and wind must contribute to enhancing the voltage profile and delivering the required reactive power compensation $[19,20]$. Promising technology has been developed to regulate the active and reactive power of DGs. For example, some photovoltaic (PV) inverters incorporate special self-commutated line inverters and wind power plants using a doubly fed induction generator that can absorb and supply reactive power at various loading conditions. The capacity of solar and wind power generating units to support reactive power must be further improved through integration of STATCOMS, SVC, and other reactive support equipment, appropriately located and sized [12,21]. Various categories of DGs are described in the literature [18,22-24], as follows:

- Type I: DGs that inject only active power, e.g., PV systems.

- Type II: DGs that inject only reactive power, e.g., synchronous compensators.

- $\quad$ Type III: DGs that inject active power but absorb reactive power, e.g., induction generators.

- Type IV: DGs that inject both active and reactive power, e.g., synchronous generators.

The DGs considered in this paper (i.e., Type IV) inject active and reactive power. However, non-optimal DG placement and sizing increases power losses and influences the voltage profile of the power system.

A number of analytical and optimization-based approaches have been suggested in the literature for DG placement, sizing, and distribution network reconfiguration. Each of these studies has at least one main objective, and methods followed to achieve this objective. Aman et al. [12] proposed a hybrid particle swarm optimization method to find the optimal solution for maximizing loadability. Guan et al. [25] considered feeder reconfiguration with the presence of various DG models with the main objective of reducing real power loss. An analytical method of feeder overcurrent protection under conditions of high penetration of renewable energy resources connected to the distribution network has been considered [26]. The impacts of optimal allocation of renewable DGs in radial distribution networks in different optimization methods were discussed in [27,28]. Quezada et al. [29] presented an approach to determine yearly power loss fluctuations when DGs with different penetration and dispersal levels are connected to a distribution system. According to the study results, the variation of power loss as a function of DG penetration level depicts a characteristic U-shaped trajectory. Jain et al. [30] tried to reduce active power loss and enhance voltage stability via the installation of multiple distributed generators. A two-stage approach for evaluating the optimal network topologies to enhance the available delivery capability of distribution networks in support of multiple renewable energies was discussed in [31]. Tolabi et al. [32] discussed reconfiguration and optimal placement of 
distributed generators with the objectives of power loss reduction and voltage profile enhancement. The authors also considered load balancing to make the system stable.

Chen et al. [33] proposed a model to reduce the overall cost of distribution networks using network reconfiguration and reactive power control of DGs. In recent years, distribution networks have faced several problems because of increasing energy demand and risky operational constraints. Essallah et al. [34] discussed a method for allocation and sizing of distributed generators to improve the voltage profile and reduce the total power dissipation in the electrical grid. The authors also recommended that power utilities effectively develop and exploit distribution networks to ensure continuity and reliability of customer service. Zongo et al. [35] examined minimization of active and reactive power loss, generation of reactive power, and voltage fluctuation. The authors combined the four factors into a single objective equation. However, to minimize the cost, only one distributed generator was used for the analysis.

Power system distribution networks have undergone several major changes because of the application of smart grid technology and the incorporation of distributed renewable energy resources. Din et al. [36] proposed optimal integration of DGs and distribution network reconfiguration to reduce distribution line loss and harmonic distortion. Similarly, in [37] proper coordination of load tap changers, switched shunt capacitors, step voltage regulators, and battery energy storage system (BESS) with high penetration of PVs were considered to minimize power loss and enhance voltage stability. Hung et al. [38] discussed the challenges of high penetration of distributed generation for traditional distribution networks. Power generated from distributed generators affects the power network flow direction, thereby influencing system power loss and voltage profile. The authors discussed an analytical method to compute the most favorable size and power factor of DGs to reduce energy dissipation and enhance loadability. The related literature, their main objectives, and the optimization methods followed are summarized in Table 1.

As depicted in Table 1, most of the studies focused on power loss reduction or voltage profile improvement. The other main concern was increasing the DG penetration level or maximum loadability. However, previous studies aiming to optimize both power loss reduction and DG penetration level increment while maintaining the voltage profile within the allowable limit are not yet adequate. Considering these research gaps, the contributions of this paper are:

- Power loss reduction and DG penetration level increment, while maintaining the voltage profile improvement within the permissible limit, are considered.

- Four scenarios, namely, the base case, only DNR, only DG installation, and simultaneous DG installation and DNR, are implemented using a hybrid optimization approach.

- The simulation results obtained for each scenario are compared with the base case and the references.

The remainder of this paper is arranged as follows: Section 2 describes the materials and methods followed, and Section 3 presents the particle swarm optimization algorithm. The simulation results and discussion are provided in Section 4, and a brief conclusion follows in Section 5. 
Table 1. Different objectives and optimization methods used in literatures for distributed generator (DG) placement and distribution loss reduction.

\begin{tabular}{|c|c|c|}
\hline References & Objectives & Optimization/Solution Methods Used \\
\hline Aman et al. [12] & Maximum loadability & Hybrid particle swarm optimization \\
\hline Guan et al. [25] & Power loss reduction & Decimal coded quantum particle swarm optimization \\
\hline Nassif et al. [26] & Feeder over current protection with large penetration of DGs & Analytical approach \\
\hline Ali et al. [27] & Power loss reduction & Satin Bowerbird Optimization (SBO) Algorithm and Ant Lion optimizer (ALO) Algorithm \\
\hline Gong et al. [28] & Power loss reduction and voltage profile improvement & Electromagnetism-like mechanism (ELM) \\
\hline Quezada et al. [29] & Power loss reduction & Iterative search technique with load flow \\
\hline Jain et al. [30] & Power loss reduction and voltage profile improvement & PSO \\
\hline Liu et al. [31] & Maximizing DG capacity & Binary particles swarm optimization (BPSO) \\
\hline Tolabi et al. [32] & Power loss reduction and voltage profile improvement & Combination of a fuzzy and ant colony optimization (ACO) \\
\hline Chen et al. [33] & Minimization of cost & Hybrid particle swarm optimization \\
\hline Essallah et al. [34] & Power loss reduction and voltage profile improvement & Analytical approach \\
\hline Zongo et al. [35] & Minimization of power loss and voltage deviation & PSO and Newton Raphson Power Flow (NRPF) \\
\hline Din et al. [36] & minimize line losses and total harmonic distortion (THD) & Genetic algorithm (GA) \\
\hline Aryanezhad et al. [37] & Power loss reduction and voltage profile improvement & Genetic algorithm (GA) \\
\hline Hung et al. [38] & Power loss reduction and enhancing loadability & Analytical approach \\
\hline Hamida et al. [39] & Power loss reduction and minimizing annual operating costs & Fuzzy set theory and evolutionary technique based on the Pareto optimality \\
\hline
\end{tabular}




\section{Materials and Methods}

The distribution network reconfiguration (DNR) problem is to find an appropriate configuration of a radial network that ensures minimum power loss. Thus, in this paper, in addition to DNR, DG placement and sizing to minimize real power loss and increase the DG penetration level while maintaining the voltage profile within the allowable limit is taken into account. For an n-bus distribution network, the objective function is to minimize the total active power loss $\left(P_{\text {Total Loss }}\right)$; the associated constraints are defined below:

$$
\begin{gathered}
P_{\text {Loss } 1,2}=R_{1,2} \times \frac{\left(P_{1,2}^{2}+Q_{1,2}^{2}\right)}{\left|V_{1}^{2}\right|} \\
P_{\text {Total Loss }}=\sum_{k=1}^{n} P_{\text {Loss } 1,2,3, \ldots, n}
\end{gathered}
$$

where $P_{\text {Loss } 1,2}$ and $R_{1,2}$ are the active power loss and resistance of the cable between the sending and receiving bus, respectively.

The percentage power loss reduction and the percentage DG penetration level increment can be expressed as shown in Equations (3) and (4), respectively.

$$
\begin{gathered}
\frac{P_{\text {Loss base }}-P_{\text {Loss } D G, D N R}}{P_{\text {Loss base }}} \times 100 \\
\frac{S_{D G}(k V A)}{S_{\text {Load }}(k V A)} \times 100
\end{gathered}
$$

where $P_{\text {Loss base }}$ and $P_{\text {Loss DG,DNR }}$ are the power losses of the base case and that of simultaneous DG and DNR, respectively. The DG size, voltage limit, and radiality constraints are described in Equations (5)-(8). $S_{D G}$ is the total power injected by the DGs and $S_{\text {Load }}$ is the total system load.

$$
\begin{aligned}
& 0.1 \times \sum_{k=2}^{n} S_{\text {Load }} \leq \sum_{k=2}^{n} S_{D G} \leq \sum_{k=2}^{n} S_{\text {Load }} \\
& V_{\text {min }} \leq\left|V_{k}\right| \leq V_{\text {max }}, 0.9 \leq\left|V_{k}\right| \leq 1.0
\end{aligned}
$$

$$
\text { Radiality: Status }=1 \text { (radial) }
$$

$$
\text { Status }=0 \text { (non-radial) }
$$

Voltage Stability Index for Optimal DG Placement

Maintaining a reliable and safe operation of a power system service is a crucial and demanding task. Voltage fluctuation occurs due to the incapability of the distribution system to deliver the electrical power demanded by the load. When DGs are optimally connected in the distribution system, the bus voltages will improve and voltage stability will be enhanced. To determine the optimal location of the DGs, a voltage stability index (VSI) approach is used in this paper. To analyze the VSI, consider a radial distribution network as depicted in Figure 1.

From Figure 1, the branch current $I_{12}$ can be computed using Equation (9):

$$
\begin{gathered}
I_{12}=\left[\frac{P_{2}+j Q_{2}}{V_{2}}\right]^{*} \\
V_{2} \angle \delta=V_{1} \angle 0-(R+j X) I_{12} \\
V_{2} \angle \delta=V_{1} \angle 0-(R+j X)\left[\frac{P_{2}+j Q_{2}}{V_{2}}\right]^{*}
\end{gathered}
$$




$$
\begin{gathered}
V_{2} \angle \delta=V_{1} \angle 0-(R+j X)\left[\frac{P_{2}-j Q_{2}}{V_{2} \angle-\delta}\right] \\
V_{2}^{2}=V_{1} V_{2} \angle-\delta-(R+j X)\left(P_{2}-j Q_{2}\right) \\
V_{2}^{2}=V_{1} V_{2} \cos \delta-j V_{1} V_{2} \sin \delta-(R+j X)\left(P_{2}-j Q_{2}\right) \\
\left(V_{2}^{2}+P_{2} R+Q_{2} X\right)+j\left(P_{2} X-Q_{2} X\right)=V_{1} V_{2} \cos \delta-j V_{1} V_{2} \sin \delta
\end{gathered}
$$

Separating real and imaginary parts and considering $\delta=0$ :

$$
\begin{gathered}
V_{2}^{2}+P_{2} R+Q_{2} X=V_{1} V_{2} \cos \delta \\
P_{2} X-Q_{2} X=-V_{1} V_{2} \sin \delta \\
V_{2}^{2}+P_{2} R+Q_{2} X=V_{1} V_{2} \\
P_{2} X-Q_{2} X=0 \Rightarrow R=\frac{P_{2} X}{Q_{2}} \\
V_{2}^{2}+P_{2}\left(\frac{P_{2} X}{Q_{2}}\right)+Q_{2} X=V_{1} V_{2}
\end{gathered}
$$

According to Murty et al. [40] for stable bus voltage, $b^{2}-4 a c \geq 0$. Hence the voltage stability index (VSI) will be:

$$
V_{1}^{2}-4\left(\frac{P_{2}^{2}}{Q_{2}}+Q_{2}\right) X \geq 0
$$

Rearranging:

$$
V S I=\frac{4 X}{V_{1}^{2}}\left(\frac{P_{2}^{2}}{Q_{2}}+Q_{2}\right) \leq 1
$$

where $X, V_{1}, P_{2}$, and $Q_{2}$ are the inductive resistance (ohms), voltage $(\mathrm{kV})$, real load $(\mathrm{kW})$, and reactive load (kvar), respectively, as shown in Figure 1.

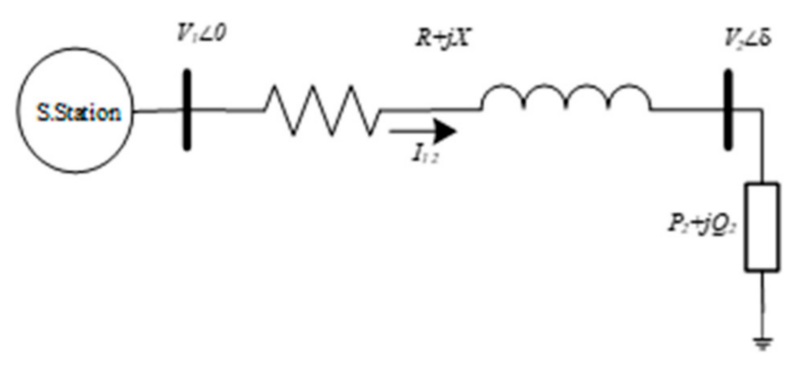

Figure 1. Equivalent circuit model for radial distribution.

The VSI magnitude must be less than one during normal operating situations. When the magnitude of VSI is approaching zero, the system is expected to be more stable. When the magnitude of VSI is high, the distribution system is vulnerable to instability. The bus with a high VSI magnitude is more sensitive and is the favored location for DG placement [40]. The single line diagrams of the 33-bus and 69-bus test systems used for this study are shown in Figure A1a,b of Appendix A, respectively. The data used for these analyses, that is, for the 33-bus and 69-bus systems, were taken from Aman et al. [12].

Using Equation (22), the candidate locations for the placement of the DGs for the 33-bus and 69-bus test systems are determined as depicted in Figure 2a,b. 


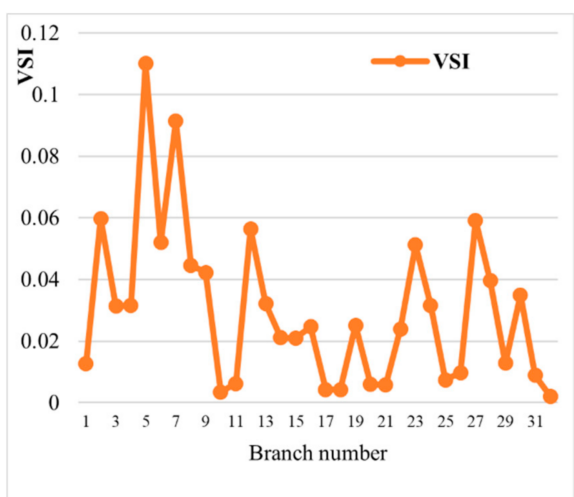

(a)

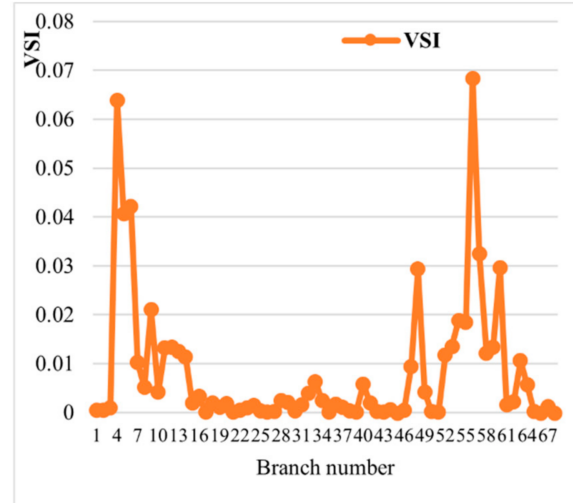

(b)

Figure 2. Voltage stability index (VSI) for: (a) 33-bus test system; (b) 69-bus test system.

As shown in Figure 2a, the maximum values of VSI are at the 6th bus (5th branch), 8th bus (7th branch), 28th bus (27th branch), and 14th bus (13th branch) for the 33-bus test system. The bus number next to the branch number with the maximum VSI value is the candidate location for DG placement. Hence, buses 6, 8, 28, and 14 are candidate buses for DG placement. Similarly, from Figure 2b, buses 57, 5, 7, and 61 are the candidate buses based on the value of VSI for the 69-bus test system. Once the candidate buses for the placement of the DGs are determined, the optimal sizes of the DGs are computed based on an analytical approach considering the constraints given in Equation (5). That is, the sizes of the DGs are incremented in steps of $5 \%$ considering minimization of power loss and increase in the penetration level of the DGs. Once the candidate locations of the DG placement were determined using VSI analysis, the PSO algorithm was used to integrate DG placement and DNR.

\section{Particle Swarm Optimization (PSO) Algorithm}

The PSO algorithm is a population-based and self-adaptive method initiated in 1995 by Kennedy and Eberhard, and adapted from food searching behavior of birds and fish (particles) [41-43]. The particles move within the search space towards the optimal position at a particular speed and frequently adjust their positions to reach the optimal location. The position and velocity of the $i$ th particle in the d-dimensional search space are denoted $x_{i}$ and $v_{i}$ as follows in Equations (23) and (24) respectively.

$$
\begin{aligned}
& x_{i}=\left(x_{i 1}, x_{i 2}, \ldots, x_{i d}\right) \\
& v_{i}=\left(v_{i 1}, v_{i 2}, \ldots, v_{i d}\right)
\end{aligned}
$$

The movement of the particles is led by their own experience $\left(P_{b e s t-i}^{k}\right)$ and the group experience $\left(G_{b e s t}^{k}\right)$. The final location visited by the $i$ th particle until the $k$ th iteration is taken as $P_{b e s t-i 1}^{k}, P_{b e s t-i 2^{\prime}}^{k} \ldots, P_{\text {best-id }}^{k}$, where the best position of all $P_{\text {best }-i}^{k}$ in the group is defined as $G_{b e s t}^{k}$. The velocity and position of every particle are updated based on Equations (25) and (26), respectively.

$$
\begin{gathered}
v_{i}^{k+1}=w v_{i}^{k+1}+c_{1} r_{1 i}\left(P_{b e s t-i}^{k}-x_{i}^{k}\right)+c_{2} r_{2 i}\left(G_{b e s t}^{k}-x_{i}^{k}\right) \\
x_{i}^{k+1}=v_{i}^{k+1}+x_{i}^{k}
\end{gathered}
$$

where $k$ is number of iterations, $w$ is inertia weight, $V_{i}$ is velocity of the $i$ th particle, $c_{1}$ and $c_{2}$ are the acceleration coefficients for cognitive and social components, respectively, and $r_{1}$ and $r_{2}$ are independently and uniformly distributed random numbers between 0 and 1 . The inertia weight is defined in Equation (27).

$$
w=w_{\max }-\frac{w_{\max }-w_{\min }}{\text { iter }_{\max }} \times \text { iter }
$$


where $w_{\max }, w_{\min }$, iter, and iter $r_{\max }$ are initial inertia weight factor, final inertia weight factor, current iteration number, and maximum iteration number, respectively. Once the candidate locations of the DGs were determined using the VSI approach, the optimal size of the DGs and the appropriate DNR were computed using the PSO algorithm to achieve minimum power loss and better DG penetration level.

\section{Results and Discussions}

Using the VSI approach for DG allocation, and the PSO algorithm for DG sizing and DNR, computations were performed to reduce the total power loss and to enhance the voltage profile of the IEEE-33-bus and IEEE-69-bus test systems. In addition to power loss reduction and voltage profile improvement, the increase in the DG penetration level was also taken into account. The simulation was performed using the MATLAB version 8.1 environment on a PC with CORE i5, $3.20 \mathrm{GHz}$, and $7.9 \mathrm{~GB}$ RAM. The results obtained for the 33-bus and 69-bus test systems are discussed as follows.

\subsection{For IEEE-33 Bus Test System}

The results obtained for the IEEE-33-bus radial distribution network, taking the base MVA of $\mathrm{S}_{\mathrm{b}}=100 \mathrm{MVA}$, and the base voltage of $\mathrm{V}_{\mathrm{b}}=12.66 \mathrm{kV}$, are described as follows. The real and reactive power loads of the system are $3715 \mathrm{~kW}$ and 2300 kvar respectively. The normally closed sectional switches and tie switches for the base case scenario are assigned 1-32 and 33-37 respectively, as depicted in Figure A1a of Appendix A.

In this paper, four different scenarios are taken into account. These scenarios are: base case, only DG scenario, only DNR scenario, and simultaneous DG and DNR. The power loss reduction and voltage profile improvements in each scenario are depicted in Figures 3 and 4, respectively. Simultaneous DG installation and DNR provides the minimum power loss, that is loss reduction of $82.13 \%$, compared with the base case power loss of $211 \mathrm{~kW}$. Furthermore, a significant improvement of voltage profile and DG penetration is achieved relative to other scenarios. When we consider only DG placement and increase the size of the DG for a better penetration level, the voltage profile near the DG location point is higher (more than 1 PU), as shown in Figure 4. This voltage increase is one of the limitations of the scenario of only DG placement. However, when the proposed method is used, the voltage profile is improved and smoothed (near to $1 \mathrm{PU}$ ), the power loss reduction is improved (Figure 3), and the DG penetration level is increased from 3323.86 to $3519.38 \mathrm{kVA}$. In Table 2, the percentage power loss reduction, DG penetration level increment, the tie switches opened, voltage magnitude improvement, and other details of the proposed system are presented. The simulation results are compared with references [44-46].

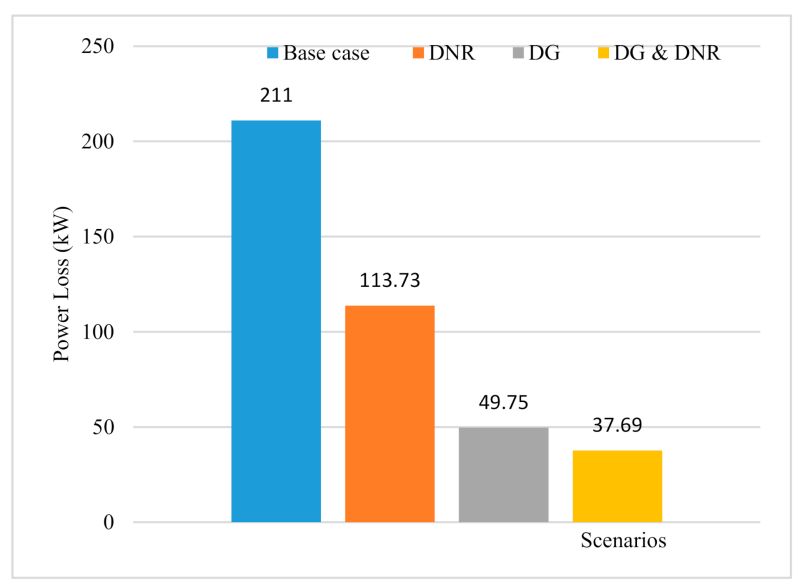

Figure 3. Power loss reduction for the 33-bus test system. 


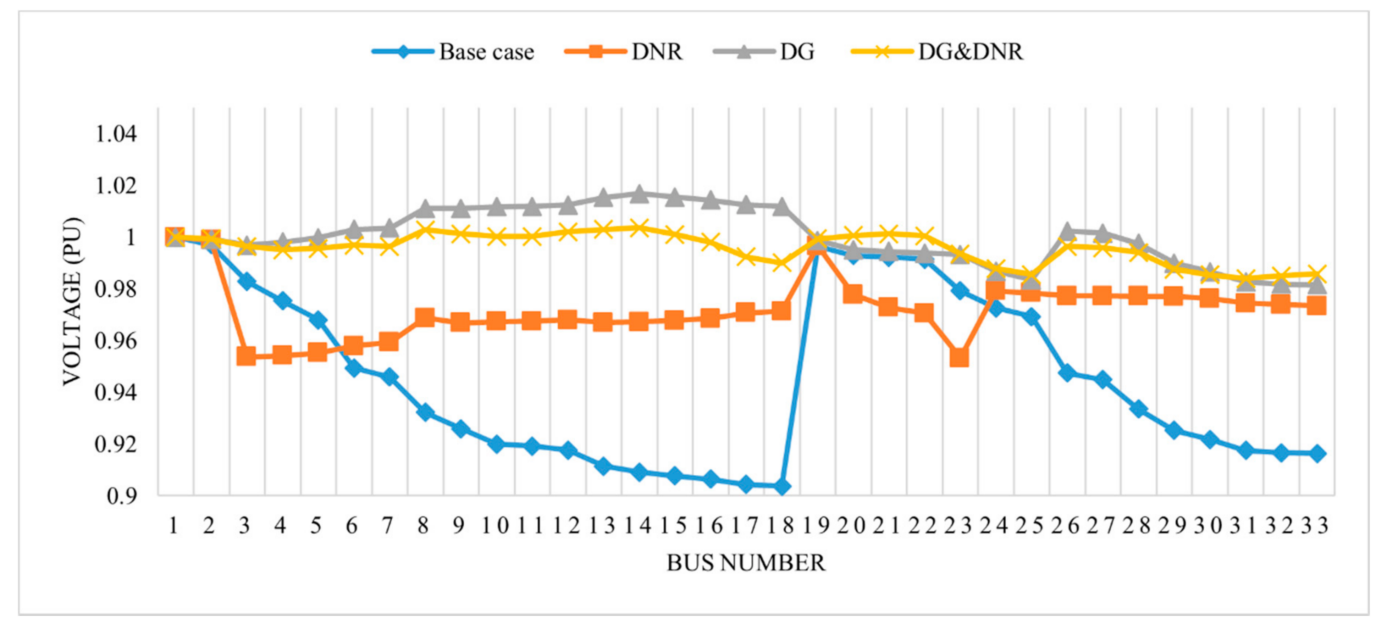

Figure 4. Voltage profile improvements for the 33 -bus test system.

For simultaneous DG installation and DNR, the percentage loss reduction and DG penetration level for the 33-bus system in comparison with references [44-46] is presented in Figure 5. As shown in the figure, the percentage power loss reduction is $82.13 \%$, which is superior to all of the references. Similarly, a significant percentage increase in DG penetration is achieved compared with references [45] and [44]. The result highlights that the proposed method optimizes both loss reduction and DG penetration level while maintaining the voltage profile within the permissible range.

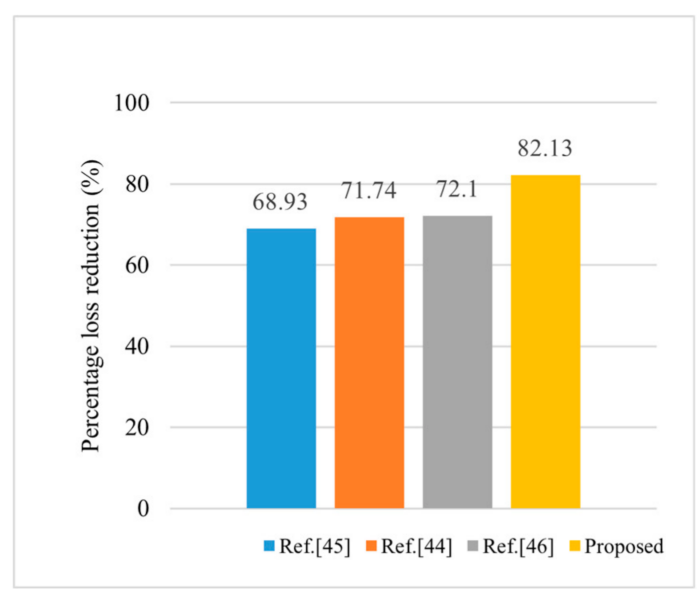

(a)

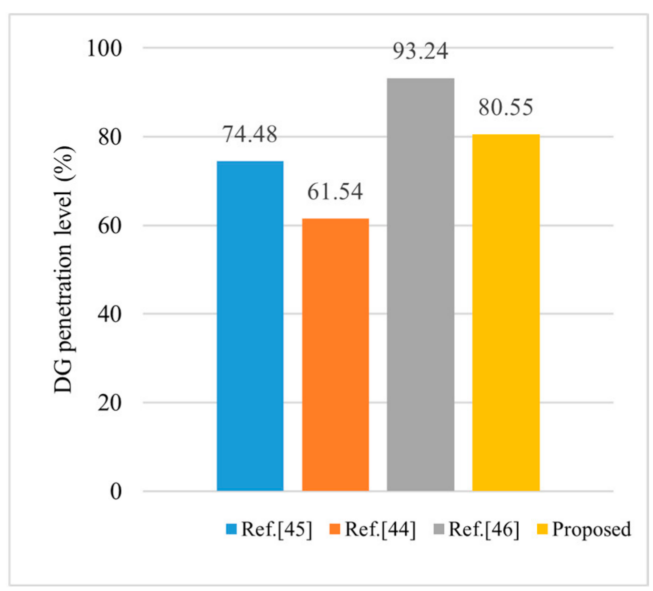

(b)

Figure 5. Comparison with references for the 33-bus test system: (a) percentage loss reduction; (b) DG penetration level increment. 
Table 2. Simulation outputs of the 33-bus test system.

\begin{tabular}{|c|c|c|c|c|c|}
\hline Scenarios & Items & Ref. [45] & Ref. [44] & Ref. [46] & Proposed \\
\hline \multirow{3}{*}{ Base case } & Switch opened & $33,34,35,36,37$ & $33,34,35,36,37$ & $33,34,35,36,37$ & $33,34,35,36,37$ \\
\hline & Power Loss $(\mathrm{kW})$ & 202.68 & 202.685 & 210.99 & 211.00 \\
\hline & Minimum voltage in p.u (bus) & 0.9108 & $0.9131(18)$ & - & $0.9038(18)$ \\
\hline \multirow{4}{*}{ Only Reconfiguration } & Switch opened & $7,9,14,28,32$ & $7,9,14,32,37$ & $7,9,14,28,32$ & $32,33,34,35,36$ \\
\hline & Power Loss $(\mathrm{kW})$ & 139.98 & 139.55 & 139.97 & 113.73 \\
\hline & $\%$ loss reduction & 30.93 & 31.15 & 33.66 & 46.1 \\
\hline & Minimum voltage in p.u (bus) & 0.9413 & $0.9378(32)$ & - & $0.9534(23)$ \\
\hline \multirow{7}{*}{ Only DG installation } & Switch opened & $33,34,35,36,37$ & $33,34,35,36,37$ & $33,34,35,36,37$ & $33,34,35,36,37$ \\
\hline & DG size & $3254.5 \mathrm{~kW}$ & $2731 \mathrm{~kW}$ & 3709.1 (kVA) & 3323.86 kVA \\
\hline & DG position & $14,24,30$ & $11,24,29$ & 14,32 & $6,8,14,28$ \\
\hline & Power Loss (kW) & 74.26 & 74.213 & 113.15 & 49.7568 \\
\hline & $\%$ loss reduction & 63.26 & 63.39 & 46.37 & 76.42 \\
\hline & \% DG penetration level & 74.48 & 62.5 & 84.89 & 76.07 \\
\hline & Minimum voltage in p.u (bus) & 0.9778 & $0.962(33)$ & - & $0.982(33)$ \\
\hline \multirow{7}{*}{ DG and DNR } & Switch opened & $8,9,27,33,36$ & $7,10,13,27,32$ & $7,10,14,28,32$ & $32,33,34,35,36$ \\
\hline & DG size & $3254.5 \mathrm{~kW}$ & $2689 \mathrm{~kW}$ & 4074.1 (kVA) & 3519.38 (kVA) \\
\hline & DG position & $14,24,30$ & $15,21,29$ & 9,25 & $6,8,14,28$ \\
\hline & Power Loss $(\mathrm{kW})$ & 62.98 & 57.287 & 58.86 & 37.70 \\
\hline & $\%$ loss reduction & 68.93 & 71.74 & 72.1 & 82.13 \\
\hline & \% DG penetration level & 74.48 & 61.54 & 93.24 & 80.55 \\
\hline & Minimum voltage in p.u (bus) & 0.9826 & $0.976(32)$ & - & $0.9841(31)$ \\
\hline
\end{tabular}




\subsection{For IEEE-69 Bus Test System}

The results obtained for the IEEE-69 bus radial distribution network with a base MVA of $\mathrm{S}_{\mathrm{b}}=100 \mathrm{MVA}$ and base voltage of $\mathrm{V}_{\mathrm{b}}=12.66 \mathrm{kV}$ are described as follows. The real and reactive power loads of the distribution network are $3801.89 \mathrm{~kW}$ and $2693.8 \mathrm{kvar}$, respectively. The normally closed sectional switches and the tie switches are numbered 1-68 and 69-73, respectively, for the base case scenario of the 69-bus test system as depicted in Figure A1b of Appendix A. Similar to the IEEE-33 bus system, four scenarios are considered. These scenarios are: base case, only DG scenario, only DNR scenario, and simultaneous DG and DNR. The power loss reduction and voltage profile improvements in each scenario are depicted in Figures 6 and 7, respectively. Power loss reduction of $89.76 \%$ and DG penetration level increment of $81.59 \%$ compared with the base case scenario are achieved from simultaneous DG installation and DNR. The voltage profile also improved significantly as depicted in Figure 7. The percentage power loss reduction, DG penetration level increment, the tie switches opened, voltage magnitude improved, and other details of the proposed system compared with the base case are presented in Table 3. When the proposed method is used, the voltage profile is improved and smoothed (near to $1 \mathrm{PU}$ ), the power loss reduction is improved (Figure 6), and the DG penetration level increases to $3801.79 \mathrm{kVA}$. The comparison of simulation results with the related references is presented in the same table.

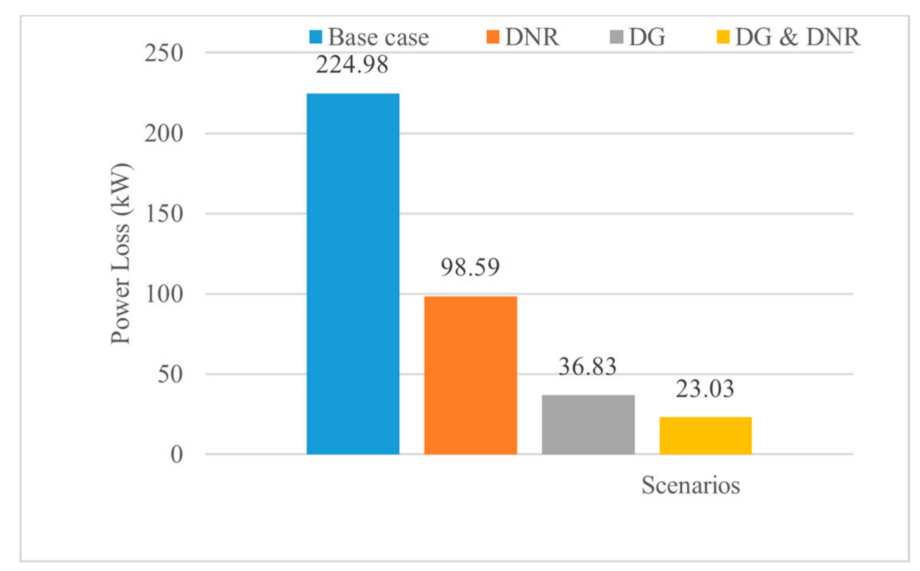

Figure 6. Power loss reduction for the 69-bus system.

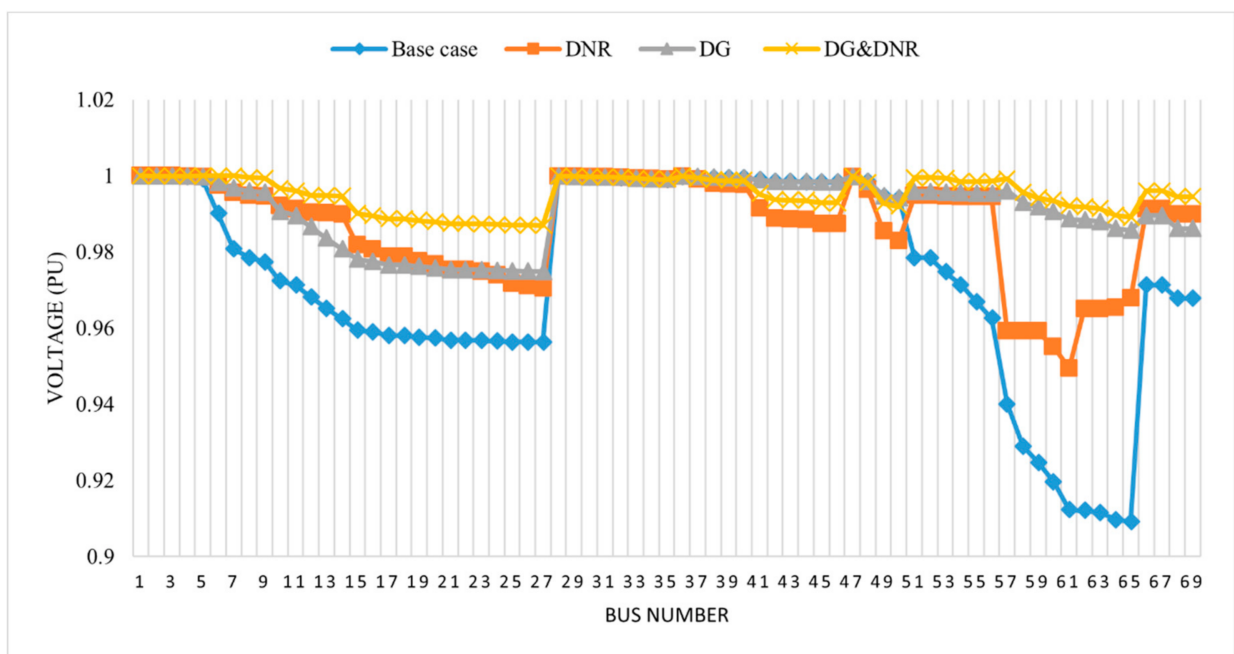

Figure 7. Voltage profile improvement for the 69-bus system. 
Table 3. Simulation outputs of the 69-bus test system.

\begin{tabular}{|c|c|c|c|c|c|}
\hline Scenarios & Items & Ref. [45] & Ref. [44] & Ref. [46] & Proposed \\
\hline \multirow{3}{*}{ Base case } & Switch opened & $69,70,71,72,73$ & $69,70,71,72,73$ & $69,70,71,72,73$ & $69,70,71,72,73$ \\
\hline & Power Loss $(\mathrm{kW})$ & 224.89 & 225 & 224.95 & 224.98 \\
\hline & Minimum voltage in p.u (bus) & 0.9092 & $0.9092(65)$ & - & $0.9092(65)$ \\
\hline \multirow{4}{*}{ Only Reconfiguration } & Switch opened & $14,57,61,69,70$ & $14,58,61,69,70$ & $14,57,61,69,70$ & $14,56,61,69,70$ \\
\hline & Power Loss $(\mathrm{kW})$ & 98.59 & 98.59 & 98.59 & 98.59 \\
\hline & $\%$ loss reduction & 56.16 & 56.19 & 56.17 & 56.18 \\
\hline & Minimum voltage in p.u (bus) & 0.9495 & $0.9495(61)$ & - & $0.9495(61)$ \\
\hline \multirow{7}{*}{ Only DG installation } & Switch opened & $69,70,71,72,73$ & $69,70,71,72,73$ & $69,70,71,72,73$ & $69,70,71,72,73$ \\
\hline & DG size & 2982.6 kW & $2431 \mathrm{~kW}$ & $3635.00(\mathrm{kVA})$ & $3401.6(\mathrm{kVA})$ \\
\hline & DG position & $2,11,18$ & $11,17,61$ & 61 & $5,7,57,61$ \\
\hline & Power Loss $(\mathrm{kW})$ & 72.44 & 72.626 & 104.86 & 36.8381 \\
\hline & $\%$ loss reduction & 67.79 & 67.72 & 53.39 & 83.63 \\
\hline & \% DG penetration level & 64.01 & 52.17 & 78.01 & 73.00 \\
\hline & Minimum voltage in p.u (bus) & 0.9890 & $0.9688(65)$ & - & $0.975(27)$ \\
\hline \multirow{7}{*}{ Simultaneous DG and DNR } & Switch opened & $14,58,64,69,70$ & $14,58,63,69,70$ & $13,17,38,57,63$ & $13,53,69,70,73$ \\
\hline & DG size & $2982.6 \mathrm{~kW}$ & $2683 \mathrm{~kW}$ & 4102.5 (kVA) & 3801.79 (kVA) \\
\hline & DG position & $2,11,18$ & $11,17,61$ & 61 & $5,7,57,61$ \\
\hline & Power Loss $(\mathrm{kW})$ & 41.13 & 37.111 & 160.81 & 23.03 \\
\hline & $\%$ loss reduction & 81.71 & 83.51 & 28.51 & 89.76 \\
\hline & \% DG penetration level & 64.01 & 57.58 & 88.05 & 81.59 \\
\hline & Minimum voltage in p.u (bus) & 0.9828 & $0.9816(63)$ & - & $0.9871(25)$ \\
\hline
\end{tabular}


From Table 3, considering the simultaneous DG installation and DNR scenario, the percentage power loss reduction and DG penetration level for the 69-bus system compared with references [44-46] is presented in Figure 8. As depicted in the figure, a percentage power loss reduction of $89.76 \%$ is achieved, which is superior to the results of all of the references. Similarly, a significant percentage increase in the DG penetration level is achieved compared with references [44,45]. The result in the 69-bus system also highlights that the proposed method optimizes both loss reduction and DG penetration level, while maintaining the voltage profile within the permissible limits. This is consistent with the important applications of dispersed power generation stated in [47,48].

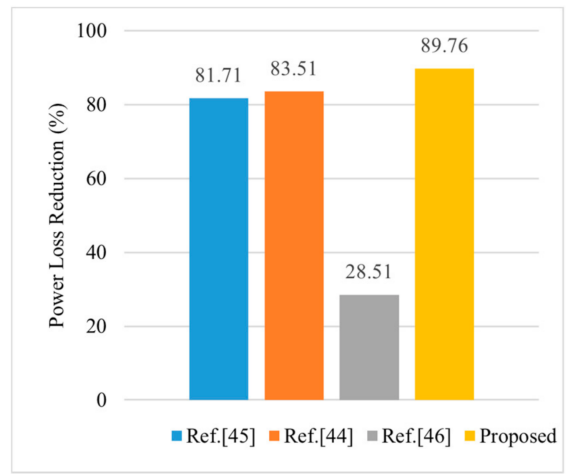

(a)

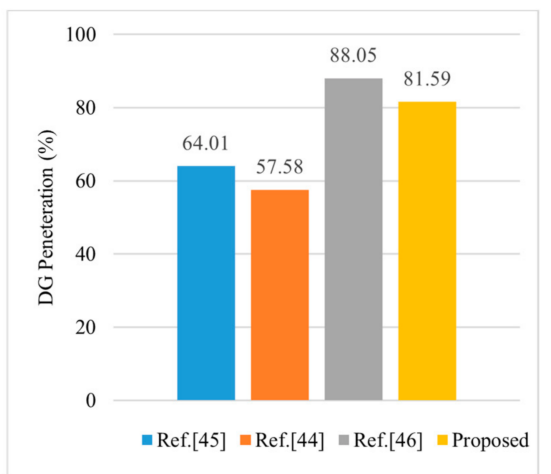

(b)

Figure 8. Comparison with references for the 69- bus test system: (a) percentage power loss reduction; (b) DG penetration increment.

\section{Conclusions}

In this paper, a hybrid of analytical and PSO approaches are discussed for minimization of distribution line losses and improvement of DG penetration level while maintaining the voltage profile improvement within the permissible limits. To achieve the proposed objective, different scenarios of DG placement and DNR are tested. These scenarios include the base case, only DNR, only DG installation, and simultaneous DG installation and DNR. Of these scenarios, simultaneous DG installation and DNR minimized power loss, maximized DG penetration level increment, and improved the voltage profile. Compared with the base case scenario, power loss reduction of $89.76 \%$ and DG penetration level increment of $81.59 \%$ were achieved for the 69 -bus test system. Similarly, power loss reduction of $82.13 \%$ and DG penetration level increment of $80.55 \%$ were attained for the 33-bus test system. It can also be concluded that there was a significant decrease in power dissipation and enhancement of the voltage profile using the DG with a lagging power factor because of its reactive power support to the system. Hence, DGs that operate with a lagging power factor and deliver reactive power to the system improve the outputs compared to a DG with a unity power factor, as depicted in Tables 2 and 3. Similarly, simultaneous DG installation and DNR provides better voltage flattening capability, in addition to power loss reduction and DG penetration level increment, compared with only DG installation and only DNR. However, when the DG penetration increases consistently, power loss increases and the voltage profile deviates from the permissible limit.

From the analysis, it is observed that when only loss reduction is considered, the DG penetration level is slightly lower. This limits the peak load handling capability of the power system. Conversely, consideration of only DG penetration level increment sometimes increases power loss and system instability due to voltage swelling. Therefore, optimizing power loss reduction and DG penetration level increment is a critical issue for stable and reliable power delivery.

Author Contributions: Conceptualization, C.-C.K. and T.M.B.; Data curation, Y.-C.H.; Formal analysis, T.M.B. and Y.-C.H.; Investigation, T.M.B. and C.-C.K.; Methodology, C.-C.K. and T.M.B.; Resources, Y.-C.H.; Supervision, C.-C.K.; Writing—original draft, T.M.B.; Writing-review \& editing, C.-C.K., Y.-C.H. and T.M.B. All authors have read and agreed to the published version of the manuscript. 
Funding: This research received no external funding.

Acknowledgments: Support for this research from the Bureau of Energy, Ministry of Economic Affairs of the Republic of China is gratefully acknowledged.

Conflicts of Interest: The authors declare no conflict of interest.

\section{Appendix A}

See Figure A1

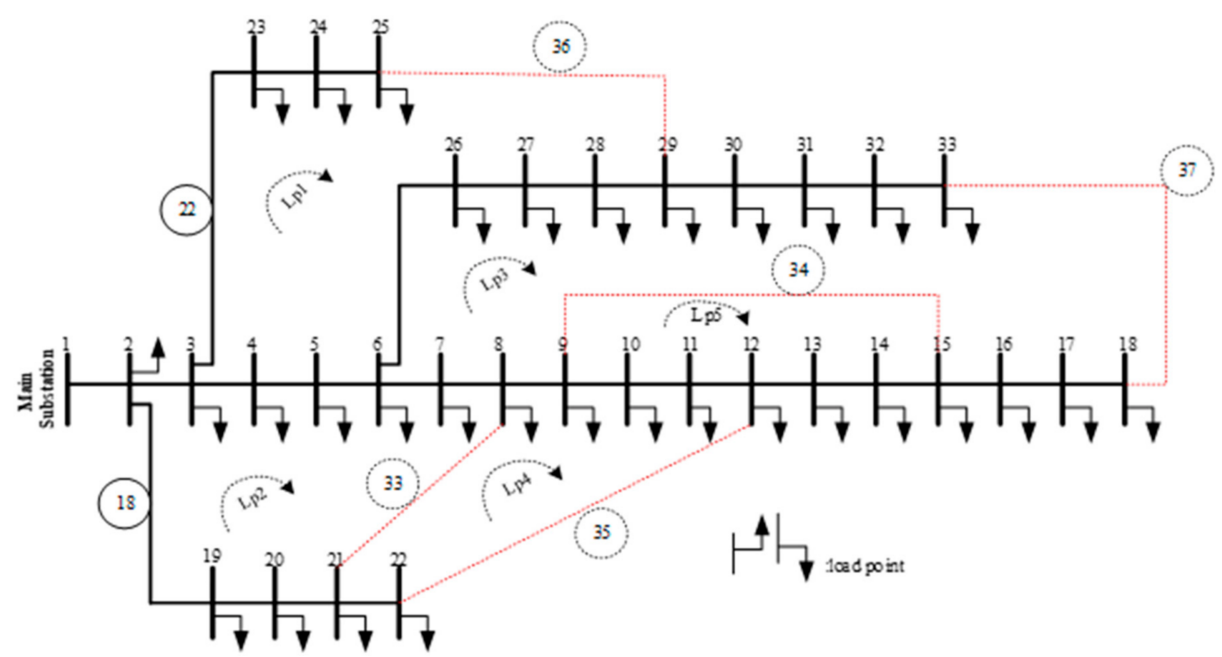

(a)

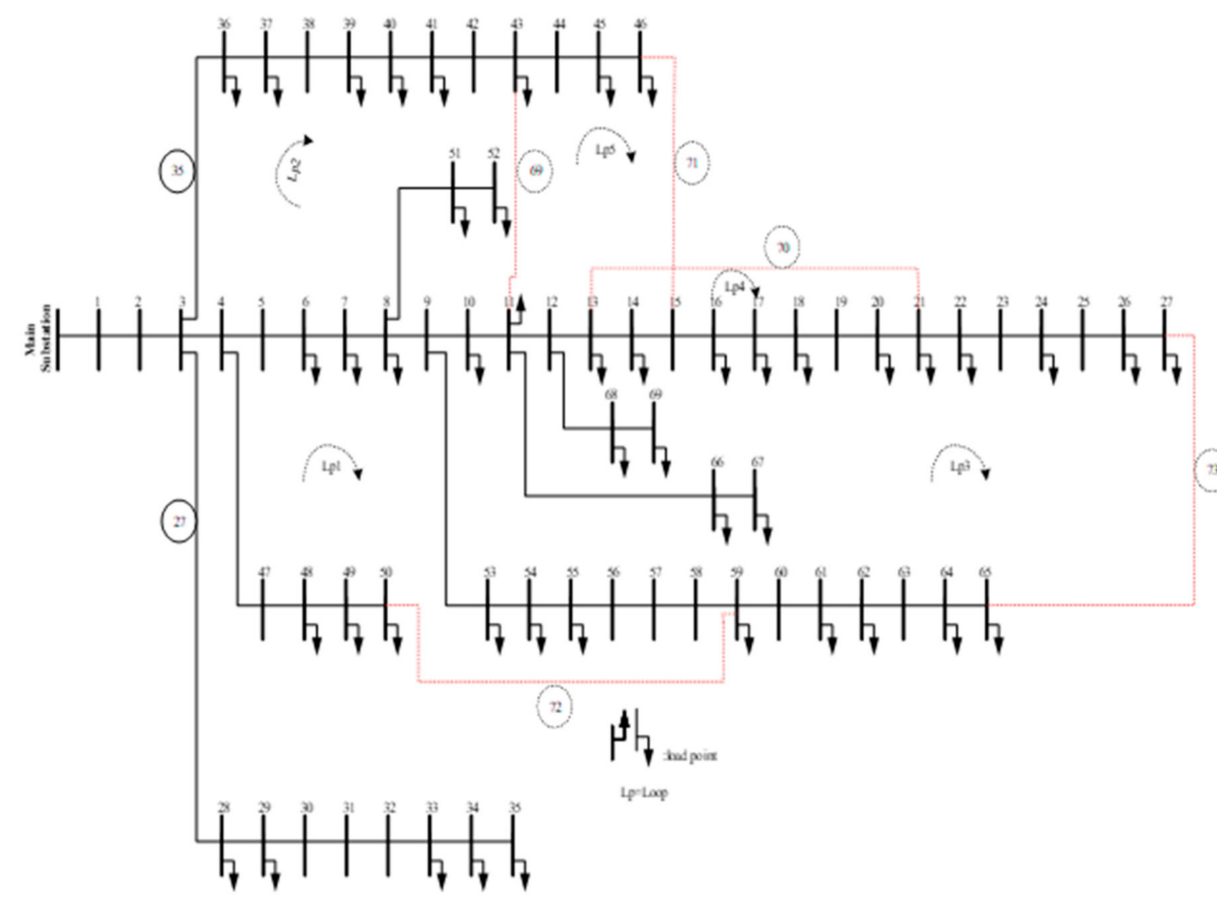

(b)

Figure A1. Single line diagram: (a) 33-bus test system; (b) 69-bus test system.

\section{References}

1. Elkadeem, M.R.; Elaziz, M.A.; Ullah, Z.; Wang, S.; Sharshir, S.W. Optimal Planning of Renewable Energy-Integrated Distribution System Considering Uncertainties. IEEE Access 2019, 7, 164887-164907. [CrossRef] 
2. Mehta, V.K.; Mehta, R. Principles of Power System, 4th ed.; S. Chand: New Delhi, India, 1995.

3. Damir, J.; Rade, C.; Josip, V.; Petar, S. Optimal Reconfiguration of Distribution Networks Using Hybrid Heuristic-Genetic Algorithm. Energies 2020, 13, 1544.

4. Sanjay, R.; Jayabarathi, T.; Raghunathan, T.; Ramesh, V.; Mithulananthan, N. Optimal Allocation of Distributed Generation Using Hybrid Grey Wolf Optimizer. IEEE Access 2017, 5, 14807-14818. [CrossRef]

5. Sultana, U.; Khairuddin, A.B.; Aman, M.; Mokhtar, A.; Zareen, N. A review of optimum DG placement based on minimization of power losses and voltage stability enhancement of distribution system. Renew. Sustain. Energy Rev. 2016, 63, 363-378. [CrossRef]

6. Zarei, M.; Zangeneh, A. Multi-Objective optimization model for distribution network reconfiguration in the presence of distributed generations. Int Trans. Electr Energy Syst. 2017, 12, 1-18. [CrossRef]

7. Selim, A.; Kamel, S.; Alghamdi, A.S.; Jurado, F. Optimal Placement of DGs in Distribution System Using an Improved Harris Hawks Optimizer Based on Single- and Multi-Objective Approaches. IEEE Access 2020, 8 , 52815-52829. [CrossRef]

8. Unahalekhaka, P.; Sripakarach, P. Reduction of Reverse Power Flow Using the Appropriate Size and Installation Position of a BESS for a PV Power Plant. IEEE Access 2020, 8, 102897-102906. [CrossRef]

9. Injeti, S.K.; Kumar, N.P. A novel approach to identify optimal access point and capacity of multiple DGs in a small, medium and large scale radial distribution systems. Int. J. Electr. Power Energy Syst. 2013, 45, 142-151. [CrossRef]

10. Mahmoud, H.A.; Huy, P.D.; Ramachandaramurthy, V.K. A review of the optimal allocation of distributed generation: Objectives, constraints, methods, and algorithms. Renew. Sustain. Energy Rev. 2017, 75, $293-312$. [CrossRef]

11. Wicaksono, D.A.; Penangsang, O.; Wibowo, R.S.; Aryani, N.K.; Putra, D.F.U. Optimizing Tie Switches Allocation and Sizing Distributed Generation (DG) Based on Maximize Loadability Simultaneously Using HPSO Algorithm; Institute of Electrical and Electronics Engineers (IEEE): Surabaya, Indonesia, 2019; pp. 102-107.

12. Aman, M.; Jasmon, G.; Bakar, A.; Mokhlis, H. A new approach for optimum simultaneous multi-DG distributed generation Units placement and sizing based on maximization of system loadability using HPSO (hybrid particle swarm optimization) algorithm. Energy 2014, 66, 202-215. [CrossRef]

13. Modarresi, J.; Gholipour, E.; Khodabakhshian, A. A comprehensive review of the voltage stability indices. Renew. Sustain. Energy Rev. 2016, 63, 1-12. [CrossRef]

14. Song, Y.; Zheng, Y.; Liu, T.; Lei, S.; Hill, D.J. Closure to Discussion on "A New Formulation of Distribution Network Reconfiguration for Reducing the Voltage Volatility Induced by Distributed Generation". IEEE Trans. Power Syst. 2020, 35, 4975-4976. [CrossRef]

15. Razavi, S.-E.; Rahimi, E.; Javadi, M.S.; Nezhad, A.E.; Lotfi, M.; Shafie-Khah, M.; Catalão, J.P. Impact of distributed generation on protection and voltage regulation of distribution systems: A review. Renew. Sustain. Energy Rev. 2019, 105, 157-167. [CrossRef]

16. Wan, H.; McCalley, J.; Vittal, V. Increasing thermal rating by risk analysis. IEEE Trans. Power Syst. 1999, 14, 815-828. [CrossRef]

17. Prada, R.; Souza, L. Voltage stability and thermal limit: Constraints on the maximum loading of electrical energy distribution feeders. IEE Proc. Gener. Transm. Distrib. 1998, 145, 573. [CrossRef]

18. Aman, M.; Jasmon, G.; Bakar, A.; Mokhlis, H. A new approach for optimum DG placement and sizing based on voltage stability maximization and minimization of power losses. Energy Convers. Manag. 2013, 70, 202-210. [CrossRef]

19. Naidji, I.; Ben Smida, M.; Khalgui, M.; Bachir, A.; Li, Z.; Wu, N. Efficient Allocation Strategy of Energy Storage Systems in Power Grids Considering Contingencies. IEEE Access 2019, 7, 186378-186392. [CrossRef]

20. Mahmoud, K.; Lehtonen, M. Simultaneous Allocation of Multi-Type Distributed Generations and Capacitors Using Generic Analytical Expressions. IEEE Access 2019, 7, 182701-182710. [CrossRef]

21. Liew, S.; Strbac, G. Maximising penetration of wind generation in existing distribution networks. IEE Proc. Gener. Transm. Distrib. 2002, 149, 256-262. [CrossRef]

22. Moravej, Z.; Akhlaghi, A.; Electrical Power and Energy Systems. A novel approach based on cuckoo search for DG allocation in distribution network. Int. J. Electr. Power Energy Syst. 2013, 44, 672-679. [CrossRef]

23. Al Abri, R.S.; El-Saadany, E.F.; Atwa, Y.M. Optimal Placement and Sizing Method to Improve the Voltage Stability Margin in a Distribution System Using Distributed Generation. IEEE Trans. Power Syst. 2012, 28, 326-334. [CrossRef] 
24. Hien, N.C.; Mithulananthan, N.; Bansal, R.C. Location and Sizing of Distributed Generation Units for Loadabilty Enhancement in Primary Feeder. IEEE Syst. J. 2013, 7, 797-806. [CrossRef]

25. Guan, W.; Tan, Y.; Zhang, H.; Song, J.; Electrical Power and Energy Systems. Distribution system feeder reconfiguration considering different model of DG sources. Int. J. Electr. Power Energy Syst. 2015, 68, $210-221$. [CrossRef]

26. Nassif, A.B. An Analytical Assessment of Feeder Overcurrent Protection with Large Penetration of Distributed Energy Resources. IEEE Trans. Ind. Appl. 2018, 54, 5400-5407. [CrossRef]

27. Ali, S.M.; Mohamed, A.-A.A.; Hemeida, A. Impact of Optimal Allocation of Renewable Distributed Generation in Radial Distribution Systems Based on Different Optimization Algorithms. In Proceedings of the 2019 International Conference on Innovative Trends in Computer Engineering (ITCE), Aswan, Egypt, 2-4 February 2019; pp. 472-478. [CrossRef]

28. Gong, Z.; Chen, Q.; Sun, K. Novel methodology solving distribution network reconfiguration with DG placement. J. Eng. 2019, 2019, 1668-1674. [CrossRef]

29. Quezada, V.H.M.; Abbad, J.R.; Gomez, T.; Roman, S. Assessment of Energy Distribution Losses for Increasing Penetration of Distributed Generation. IEEE Trans. Power Syst. 2006, 21, 533-540. [CrossRef]

30. Jain, N.; Singh, S.N.; Srivastava, S.C. Particle Swarm Optimization Based Method for Optimal Siting and Sizing of Multiple Distributed Generators; IEEE: Hyderabad, India, 2010; pp. 669-674.

31. Liu, J.; Chiang, H.-D. Maximizing Available Delivery Capability of Unbalanced Distribution Networks for High Penetration of Distributed Generators. IEEE Trans. Power Deliv. 2014, 32, 1196-1202. [CrossRef]

32. Tolabi, H.B.; Ali, M.H.; Rizwan, M. Simultaneous Reconfiguration, Optimal Placement of DSTATCOM, and Photovoltaic Array in a Distribution System Based on Fuzzy-ACO Approach. IEEE Trans. Sustain. Energy 2015, 6, 210-218. [CrossRef]

33. Chen, S.; Hu, W.; Chen, Z. Comprehensive Cost Minimization in Distribution Networks Using Segmented-Time Feeder Reconfiguration and Reactive Power Control of Distributed Generators. IEEE Trans. Power Syst. 2016, 31, 983-993. [CrossRef]

34. Essallah, S.; Khedher, A.; Bouallegue, A. Integration of distributed generation in electrical grid: Optimal placement and sizing under different load conditions. Comput. Electr. Eng. 2019, 79, 106461. [CrossRef]

35. Andric, I.; Pina, A.; Ferrao, P.; Fournier, J.; Lacarriere, B.; Lecorre, O. Assessing the feasibility of using the heat demand-outdoor temperature function for a long-term district heat demand forecast. Energy Procedia 2017, 138, 134-139. [CrossRef]

36. Din, F.U.; Ahmad, A.; Ullah, H.; Khan, A.; Umer, T.; Wan, S. Efficient sizing and placement of distributed generators in cyber-physical power systems. J. Syst. Arch. 2019, 97, 197-207. [CrossRef]

37. Aryanezhad, M. Management and coordination of LTC, SVR, shunt capacitor and energy storage with high PV penetration in power distribution system for voltage regulation and power loss minimization. Int. J. Electr. Power Energy Syst. 2018, 100, 178-192. [CrossRef]

38. Hung, D.Q.; Mithulananthan, N. Loss reduction and loadability enhancement with DG: A dual-index analytical approach. Appl. Energy 2014, 115, 233-241. [CrossRef]

39. Ben, I.; Brini, S.; Msahli, F.; Faouzi, M. Optimal network recon fi guration and renewable DG integration considering time sequence variation in load and DGs. Renew. Energy 2018, 121, 66-80.

40. Murty, V.; Kumar, A. Optimal placement of DG in radial distribution systems based on new voltage stability index under load growth. Int. J. Electr. Power Energy Syst. 2015, 69, 246-256. [CrossRef]

41. Kennedy, J.; Eberhart, R. Particle Swarm Optimization; IEEE: Indianapolis, IN, USA, 1995; pp. $1942-1948$.

42. Kennedy, J.; Eberhart, R. A New Optimizer Using Particle Swarm Theory; IEEE: Washington, DC, USA, 2012; pp. 39-43.

43. Jamian, J.J.; Abdullah, M.N.; Mokhlis, H.; Mustafa, M.W.; Bakar, A.H.A. Global Particle Swarm Optimization for High Dimension Numerical Functions Analysis. J. Appl. Math. 2014, 2014, 1-14. [CrossRef]

44. Bayat, A.; Bagheri, A.; Noroozian, R. Optimal siting and sizing of distributed generation accompanied by reconfiguration of distribution networks for maximum loss reduction by using a new UVDA-based heuristic method. Int. J. Electr. Power Energy Syst. 2016, 77, 360-371. [CrossRef]

45. Thanh, T.; Viet, A.; Anh, T. A novel method based on adaptive cuckoo search for optimal network reconfiguration and distributed generation allocation in distribution network. Int. J. Electr. Power Energy Syst. 2016, 78, 801-815. 
46. Aman, M.M.; Mokhlis, H.; Jasmon, G.B.; Abu Bakar, A.H. Optimum tie switches allocation and DG placement based on maximisation of system loadability using discrete artificial bee colony algorithm. IET Gener. Transm. Distrib. 2016, 10, 2277-2284. [CrossRef]

47. Seritan, G.; Porumb, R.; Cepisca, C.; Grigorescu, S.D. Integration of Dispersed Power Generation. In Electricity Distribution-Intelligent Solutions for Electricity Transmission and Distribution Networks; Karampelas, K., Ekonomu, L., Eds.; Springer: Berlin, Germany, 2016; pp. 27-61.

48. Seritan, G.; Tristiu, I.; Fierascu, G.; Vatu, R. Assessment for Efficient Operation of Smart Grids Using Advanced Technologies. In Proceedings of the 2018 International Conference and Exposition on Electrical and Power Engineering (EPE), Iasi, Romania, 18-19 October 2018; pp. 0901-0905.

Publisher's Note: MDPI stays neutral with regard to jurisdictional claims in published maps and institutional affiliations.

(C) 2020 by the authors. Licensee MDPI, Basel, Switzerland. This article is an open access article distributed under the terms and conditions of the Creative Commons Attribution (CC BY) license (http://creativecommons.org/licenses/by/4.0/). 